\section{Detection of Glu-Glu- Tagged Proteins in Mammalian Cell Culture Media by Dot Immunoblotting}

BioTechniques 28:934-937 (May 2000)

\begin{abstract}
A dot immunoblotting technique has been developed to estimate the relative expression levels of tagged recombinant human proteins in mammalian cell culture media. Variations in sample denaturation, blocking agents and membrane composition and treatment were used to optimize the signal-to-noise ratio of the defined procedure. The method is rapid, with sensitivity extending to the low nanomolar range for a number of recombinant proteins. This technique should have general utility for antibodybased measurements of other tagged and non-tagged proteins in cell culture media or in biological fluids.
\end{abstract}

\section{INTRODUCTION}

Screening of mammalian cell culture supernatants for the expression of an exogenous protein is required at virtually all stages in the production of recombinant proteins. Optimization for transfection efficiency, selection of clones and product amplification depend on the rapid identification of cultures expressing the desired level of protein. Techniques that are commonly used to assess protein expression include separation of a protein mixture by SDSPAGE, followed by staining with a variety of protein stains such as Coomassie Blue $^{\circledR}$ or silver, SDS-PAGE-Western blotting or ELISAs using protein-specific antibodies $(1,3)$. The relative advantages and disadvantages of each of these techniques depend on the speed and sensitivity required, the presence of interfering substances in the culture media and the availability of proteinspecific antibodies.

As part of a strategy for the highthroughput production of many novel recombinant proteins, it was necessary to develop a fast, sensitive method for measuring the relative levels of protein expression in mammalian cell cultures. Here, we report on the development of a dot immunoblotting procedure used to estimate the concentration of $\mathrm{N}$ - or C-terminal Glu-Glu-tagged proteins in cell culture media.

\section{MATERIALS AND METHODS}

Immobilon ${ }^{\mathrm{TM}}-\mathrm{P},-\mathrm{NC}$ and -PSQ transfer membranes were obtained from Millipore (Bedford, MA, USA). The Minifold ${ }^{\circledR}$ I dot blot system was purchased from Schleicher \& Schuell (Keene, NH, USA). Murine antibodies to the Glu-Glu peptide, EYMPME, were obtained from Covance (Madison, WI, USA), and HRP-conjugated goat anti-mouse IgG antibodies were obtained from Santa Cruz Biotechnology (Santa Cruz, CA, USA). West Dura Extended Duration ${ }^{\circledR}$ substrate and Super Signal Ultra ${ }^{\circledR}$ for ECL $^{\mathrm{TM}}$ were obtained from Pierce Chemical (Rockford, IL, USA); Hyperfilm ${ }^{\mathrm{TM}}$ ECL and Hoeffer TE22 blotting apparatus were both purchased from Amersham Pharmacia Biotech (Piscataway, NJ, USA). Tris-Glycine 4\%-20\% polyacrylamide gradient gels and sample buffer were obtained from Novex (San Diego, CA, USA). Supported nitrocellulose paper $(0.2 \mu \mathrm{m})$ was purchased from Bio-Rad Laboratories (Hercules, CA, USA). All other chemicals were purchased from Sigma (St. Louis, MO, USA) unless otherwise noted. Water was prepared by Milli-Q ${ }^{\circledR}$ filtration (Millipore).

\section{Dot Immunoblotting of Mammalian Cell Culture Conditioned Media}

A template of twofold serial dilutions of serum-free conditioned media from transfected BHK cells was prepared in a deep 96-well microplate by initially transferring $285 \mu \mathrm{L}$ conditioned cell culture media into a well containing $15 \mu \mathrm{L} 20 \times$ denaturing buffer [Buffer D, $200 \mathrm{mM}$ Tris-HCL (pH 7.4), $1 \mathrm{M} \mathrm{NaCl}, 0.1 \mathrm{M} \beta$-mercaptoethanol and $0.08 \%$ Triton $\left.{ }^{\circledR} \mathrm{X}-100\right]$ ]. A standard curve, starting at $75 \mathrm{ng}$ standard GluGlu tagged protein, was set up in the same manner in a separate row of wells on each plate. All serial dilutions were prepared in a final concentration of $1 \times$ Buffer D. The plates were covered and incubated at $65^{\circ} \mathrm{C}$ for $10 \mathrm{~min}$. The dot blot apparatus was assembled according to the manufacturer's instructions and the Immobilon-P transfer membrane was prewetted in $100 \%$ methanol for 15 $\mathrm{s}$ and rinsed in water for $2 \mathrm{~min}$. No filter paper backing was used. When other transfer membranes were tested, they were pretreated according the manufacturer's instructions. The membrane was placed on the dot blot apparatus while still wet, and each well was loaded under vacuum with $100 \mu \mathrm{L}$ from the appropriate well of the sample template.

After the media was vacuum-filtered through each well, the wells were rinsed twice with $100 \mu \mathrm{L}$ Buffer W [10 $\mathrm{mM}$ Tris- $\mathrm{HCl}(\mathrm{pH} 7.4)$ and $50 \mathrm{mM}$ $\mathrm{NaCl}$. When the rinses were complete, the vacuum was turned off and the membrane was placed in $50 \mathrm{~mL} 1 \times$ Buffer D and incubated at $65^{\circ} \mathrm{C}$ for 10 min. Each membrane was then rinsed with water, placed between two sheets of Whatman ${ }^{\circledR} 3 \mathrm{M}$ filter paper and dried in a vacuum oven at $100^{\circ} \mathrm{C}$ for $30 \mathrm{~min}$. After drying, the membrane was rinsed with methanol for $15 \mathrm{~s}$ and then with water for $2 \mathrm{~min}$.

The rinsed membrane was then immediately placed in $100 \mathrm{~mL}$ Buffer B (Buffer W containing 0.05\% Tween ${ }^{\circledR}$ 20 and $0.5 \%$ nonfat dry milk) and gently agitated on an orbital shaker for 30 min at room temperature. Each membrane was quickly rinsed with Buffer T (Buffer W containing 0.05\% Tween 20); fresh Buffer B was added and each membrane was incubated with $0.1 \mu \mathrm{g}$ anti Glu-Glu antibody/mL for $1 \mathrm{~h}$ at room temperature or overnight at $4^{\circ} \mathrm{C}$. The antibody-containing solution was discarded, and each membrane was washed $3 \times$ for 10 min with Buffer T. After a quick rinse with Buffer W, the membranes were incubated with 0.1 $\mathrm{mg} / \mathrm{mL}$ HRP-conjugated goat antimouse IgG in Buffer B for $1 \mathrm{~h}$ at room temperature with gentle shaking. Each membrane was then washed $3 \times$ for 10 min each with Buffer $\mathrm{T}$ and quickly rinsed sequentially with Buffer $\mathrm{W}$ and water. The membranes were then placed in a sheet protector and incubated with the ECL substrate according to the manufacturer's instructions and 
placed on a sheet of Kodak XAR-5 ${ }^{\mathrm{TM}}$ film (Eastman Kodak, Rochester, NY, USA) for development by autoradiography, or the membranes were placed directly in a Lumi Imager ${ }^{\mathrm{TM}}$ (Roche Molecular Biochemicals, Indianapolis, IN, USA) for quantitation.

\section{SDS-PAGE and Western Blotting}

Samples of BHK conditioned media were prepared for electrophoresis by mixing them with an equal volume of $2 \times$ Tris-glycine sample buffer containing $0.2 \mathrm{M}$ dithiothreitol. All samples were heated at $100^{\circ} \mathrm{C}$ for $5 \mathrm{~min}$ immediately before loading the gels. Electrophoresis and transfer of proteins to nitrocellulose membranes were conducted according to the manufacturer's instructions. The transfer buffer used contained $25 \mathrm{mM}$ Tris, $0.2 \mathrm{M}$ glycine and $20 \%$ methanol. Following transfer at $500 \mathrm{~mA}$ for $1 \mathrm{~h}$ or $50 \mathrm{~mA}$ for $18 \mathrm{~h}$,

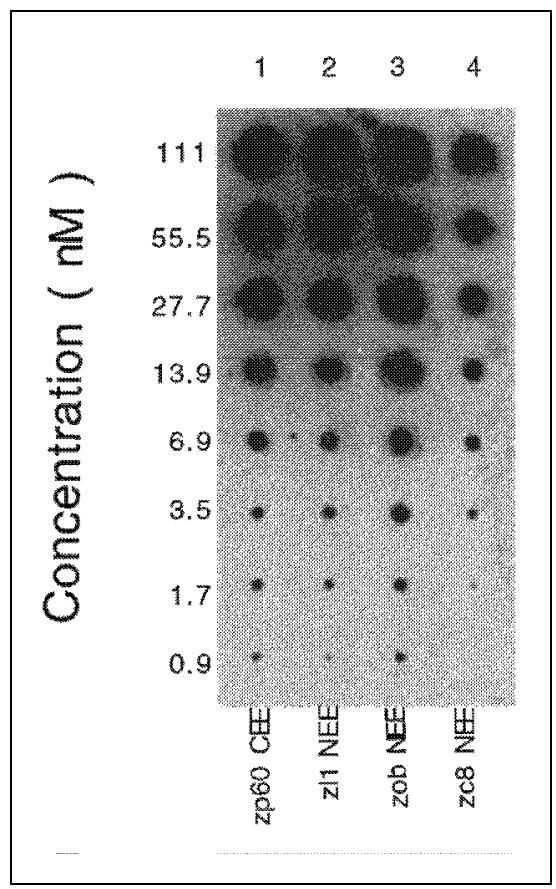

Figure 1. Dot immunoblotting of BHK conditioned media for detection of recombinant Glu-Glu-tagged protein. Samples of BHK conditioned media were spiked at $111 \mathrm{nM}$ with one of four purified Glu-Glu-tagged proteins (Lanes 1-4). Serial dilutions (Rows A-H) were then made into BHK conditioned media and the immunoblotting was carried out as described in the Materials and Methods section. The apparent molecular weights of the proteins were zp60 CEE, 7000 Da; zl1 NEE, 18000 Da; zobNEE, $17000 \mathrm{Da}$; and zc8NEE, $8400 \mathrm{Da}$. the membranes were blocked for 10 min at room temperature with Western A buffer $[50 \mathrm{mM}$ Tris- $\mathrm{HCl}$ (pH 7.4), 5 mM EDTA, 0.05\% Igepal CA-630, 150 $\mathrm{mM} \mathrm{NaCl}$ and $0.25 \%$ gelatin] containing $10 \%$ nonfat dry milk. The membranes were quickly rinsed with Western A buffer and incubated with $0.1 \mu \mathrm{g}$ anti-Glu-Glu antibody/mL of Western A buffer containing $2.5 \%$ nonfat dry milk. After gentle agitation for $1 \mathrm{~h}$ at room temperature or overnight at $4^{\circ} \mathrm{C}$, the membranes were washed $3 \times$ with Western A buffer for $10 \mathrm{~min}$ each. Fresh Western A buffer containing $2.5 \%$ nonfat dry milk and $0.2 \mu \mathrm{g} / \mathrm{mL}$ HRP-conjugated goat antimouse IgG were added, and the membranes were incubated for $1 \mathrm{~h}$ at room temperature with gentle agitation. The membranes 


\section{Short Technical Reports}

were then washed $3 \times$ for 10 min each in Western A buffer, followed by a quick rinse in water. Next, the membranes were visualized with Super Signal Ultra according to the manufacturer's instructions and quantitated using the Lumi Imager as described before. Statistical analysis was performed using the software package Stata.

\section{RESULTS AND DISCUSSION}

Some preliminary experiments were undertaken to examine the effects of sample denaturation, membrane type and treatment and the effects of various blocking agents on the signal-to-noise ratio of the dot immunoblotting procedure. Each parameter was tested with a number $(n=4-6)$ of different purified Glu-Glu-tagged proteins that were spiked at $1-100 \mathrm{nM}$ concentrations into samples of BHK conditioned media.

\section{Sample Denaturation}

Although most Glu-Glu-tagged proteins we analyzed could be adequately detected without prior reduction and denaturation, the dot blot signal intensity for most of these proteins was increased twofold to threefold by prior incubation at $65^{\circ} \mathrm{C}$ for $10 \mathrm{~min}$ in the presence of 5 $\mathrm{mM} \beta$-mercaptoethanol. Inclusion of $0.002 \%-0.004 \%$ SDS or Triton X-100 in the denaturation buffer produced a further two- to threefold increase in signal intensity. These data are consistent with the notion that the access of the anti-tag antibody to the Glu-Glu tag is restricted in the native state of these recombinant proteins. On the other hand, concentrations of SDS above $0.004 \%$ and of Triton X-100 above $0.016 \%$ completely prevented detection by immunoblotting, which suggests that protein binding to the membranes was inhibited or the Glu-Glu tag was rendered inaccessible to antibody under these conditions. Since the useful concentration range with Triton X-100 was somewhat broader than with SDS, we have used the former detergent for the remainder of our experiments.

\section{Membrane Composition and Treatment}

Compared to Immobilon-NC or -PSQ membranes, the Immobilon-P membranes that were prepared as described earlier produced the highest signal-to-noise ratio. The most consistent results were obtained with prewetted membranes assembled in the dot blot apparatus without paper backing. Of the three membranes tested, Immobilon-PSQ appeared to have the highest level of nonspecific background staining. The dot blot signal intensity for most of the proteins analyzed was also increased by a post-blotting incubation 


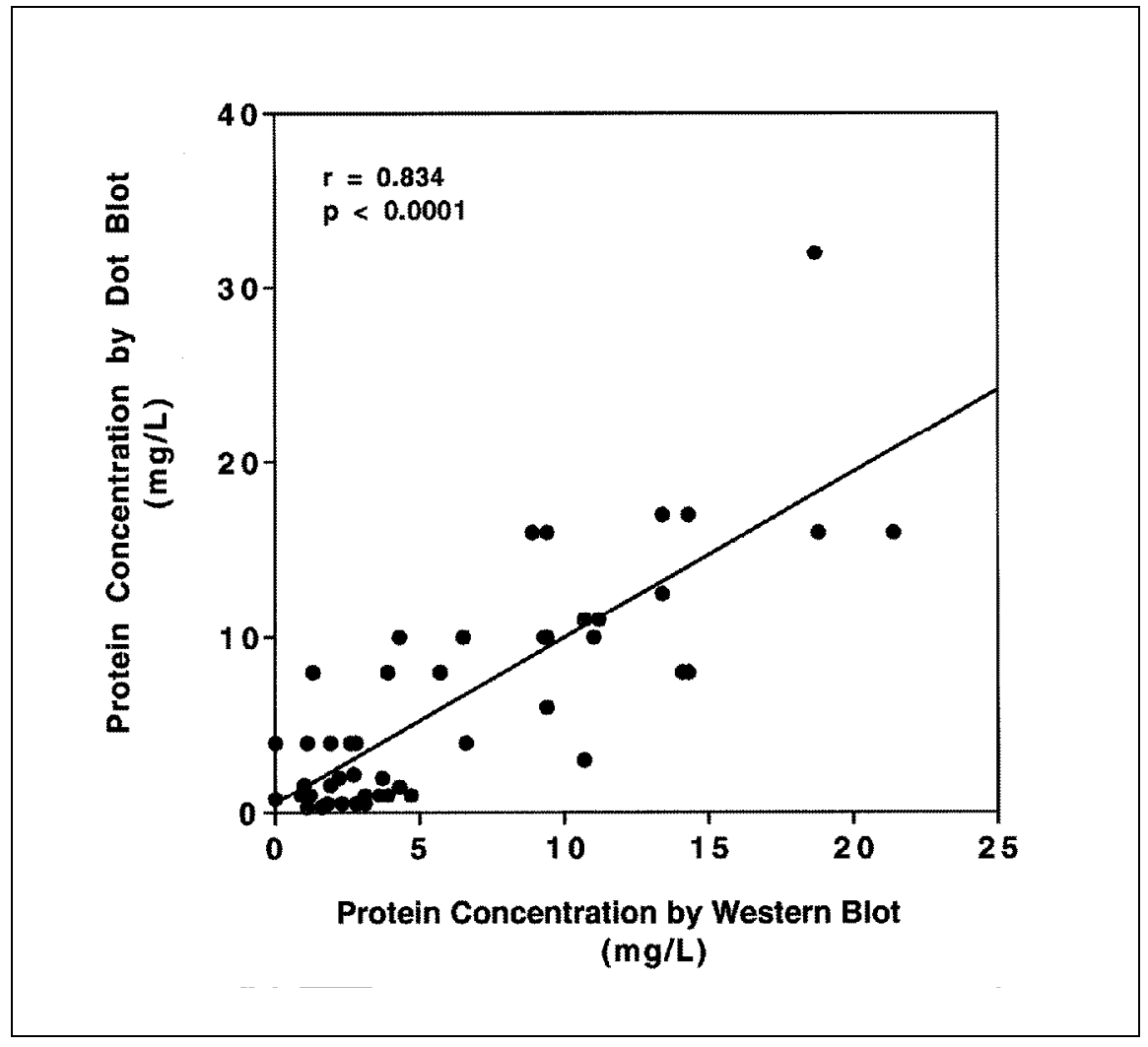

Figure 2. Comparison of dot immunoblotting with SDS-PAGE Western blot analysis for estimating the levels of Glu-Glu-tagged protein in BHK conditioned media. Duplicate samples of conditioned media from 51 different BHK clones representing six different recombinant Glu-Glu-tagged proteins (4-12 different clones for each protein) were taken for analysis by dot or Western blotting as described. Each point represents a concentration determined from serial dilution of the culture medium from a single clone of BHK cells.

at $65^{\circ} \mathrm{C}$ for $10 \mathrm{~min}$ in the presence of $0.004 \%$ Triton $\mathrm{X}-100$ and $5 \mathrm{mM} \beta$ mercaptoethanol. No further increase was observed by increasing the temperature to $100^{\circ} \mathrm{C}$. Compared to drying the membrane at room temperature or drying at room temperature in a vacuum dessicator, a further $40 \%-50 \%$ increase in signal intensity was observed by drying the membranes at $100^{\circ} \mathrm{C}$ for $30 \mathrm{~min}$ in a vacuum oven.

\section{Blocking Agents}

A number of agents are reported to be effective in reducing nonspecific binding of antibodies to membranes in immunoblotting experiments (1-3). When compared to blocking in $0.5 \%$ nonfat dried milk, blocking with $1 \%$ PVP-40 was inconsistent with a high level of background antibody staining that is often observed. In contrast, nonfat dried milk at $0.5 \%, 2.5 \%$ or $10 \%$ six different Glu-Glu-tagged recombinant proteins (representing 51 different BHK clones) were taken for analysis (Figure 2). The relative concentrations of Glu-Glu-tagged proteins in the conditioned media measured by the two procedures was highly correlated $(\mathrm{r}=$ $0.834, P<0.0001)$.

In summary, the outlined procedure provides a rapid, sensitive method for measuring the levels of recombinant Glu-Glu-tagged protein secreted into the culture media of mammalian cells. We expect this procedure will useful for antibody-based measurement of other tagged and non-tagged recombinant proteins in cell culture media or biological fluids.

\section{REFERENCES}

1.Gallagher, S., S.E. Winston, S.A. Fuller and J.G.R. Hurrell. 1990. Immunoblotting and immunodetection, p. 10.8.01-10.8.14. In F.A. Ausubel, R. Brent, R.E. Kingston, D.D. Moore, G. Seidman, J.A. Smith and K. Struhl (Eds.), Current Protocols in Molecular Biology. Greene Publishing and Wiley Interscience, New York.

2.Goncalves, C.A., C. Gottfried, T. Kommers and R. Rodnight. 1997. Calcium-modulated proteins change their immunoreactivity in the presence of $\mathrm{Ca}^{2+}$ : a study of antibody recognition in a dot immunoassay for calmodulin, calcineurin ( $\beta$-subunit), and S100B. Anal. Biochem. 253:127-130.

3.Renner, S.W. 1988. Immunoblotting and dot immunoblotting. Arch. Pathol. Lab. Med. 112:780-786.

The authors would like to thank the Cloning, Mammalian Expression and Protein Biochemisty Groups at ZymoGenetics for providing the BHK conditioned media and purified Glu-Glu-tagged proteins. Address correspondence to Dr. Jeff $L$. Ellsworth, ZymoGenetics, Inc., 1201 Eastlake Ave. East, Seattle, WA 98102, USA. Internet: ellsworj@zgi.com

Received 29 November 1999; accepted 2 February 2000.

Jeff L. Ellsworth, Nels Hamacher, Nancy Bagwell and James W. West ZymoGenetics Seattle, WA, USA 